\title{
The use of protein array to identify targetable receptor tyrosine kinases for treatment of human colon cancer
}

\author{
ASAHIRO MORISHITA ${ }^{1}$, JIAN GONG ${ }^{2}$, TAKAKO NOMURA ${ }^{2}$, HIROHITO YOSHIDA $^{2}$, \\ KUNIHIKO IZUISHI ${ }^{3}$, YASUYUKI SUZUKI ${ }^{3}$, YOSHIO KUSHIDA ${ }^{4}$, REIJI HABA ${ }^{4}$, \\ JEANINE D'ARMIENTO ${ }^{1}$ and TSUTOMU MASAKI ${ }^{2}$
}

\author{
${ }^{1}$ Department of Medicine, Columbia University College of Physicians \& Surgeons, New York, NY 10032, USA; \\ Departments of ${ }^{2}$ Gastroenterology and Neurology, ${ }^{3}$ Gastroenterological Surgery, ${ }^{4}$ Diagnostic Pathology, \\ Kagawa University School of Medicine, Miki-cho, Kida-gun, Kagawa 761-0793, Japan
}

Received May 7, 2010; Accepted June 21, 2010

DOI: 10.3892/ijo_00000733

\begin{abstract}
Several studies have reported that activated receptor tyrosine kinases (RTKs) are highly expressed in colon cancer and may promote tumor growth and survival. However, there is little information available as to the function and signaling of RTKs in colon cancers. In the present study, we performed protein array technology to determine the expression status of various RTKs that are activated in colon cancer compared to normal colonic cells and tissues. Of the 42 different phospho-RTKs, 5 (ErbB2, FGFR1, FGFR2a, FGFR3 and MSPR) were activated in Caco-2, SW480, WiDr, Lovo colon cancer cell lines and cancerous tissues. In order to determine the effect of inhibition of RTKs, especially ErbB2, athymic nude mice bearing xenograft tumors were treated with the ErbB2-targeting drug trastuzumab alone, or in combination with 5-Fluorouracil (5-FU). Similar to the treatment of 5-FU alone, trastuzumab suppressed the growth of colon cancer. Combination therapy of trastuzumab and 5-FU inhibited tumor growth significantly compared to the treatment of 5-FU alone or trastuzumab alone. In addition, xenograft tumors were also analyzed by phospho-MAPK protein array. The activity of $\mathrm{Akt} 3 / \mathrm{PKB} \gamma$ was inhibited with 5 -FU alone and trastuzumab, indicating that trastuzumab may inhibit colon cancer growth through ErbB2-Akt3/PKB $\gamma$ signaling. These data demonstrate that ErbB2 could be an important candidate for colon cancer therapy and the addition of trastuzumab to 5-FU therapy might augment the clinical response in colon cancer patients. Therefore, the analysis of phospho-RTK expression by protein array as a useful tool might identify novel therapies for individual patients with colon cancer.
\end{abstract}

Correspondence to: Dr Asahiro Morishita, Columbia University, 630 West 168th Street, College of Physicians \& Surgeons, 9-449, New York, NY 10032, USA

E-mail: am2925@columbia.edu

Key words: protein array, RTKs, colon cancer therapy

\section{Introduction}

Colorectal cancer is the fourth leading cause of death in all cancers and is responsible for approximately 500 deaths per 100,000 persons per year in the world (1). Despite the increasing emphasis on screening and prevention, at least 5\% of patients will present with locally unresectable disease with tumors fixed to critical structures or organs not amenable nor appropriate for radical resection (2). In such patients, incomplete resection alone (3) or radiation therapy alone (4), results in few long-term survivors. Therefore, there is a strong demand for new curative approaches to colon cancer therapy.

The protein tyrosine kinases are a large and diverse multigene family found only in Metazoans. Their principle function involves the regulation of multicellular aspects of the organism. Cell to cell signaling concerning growth, differentiation, adhesion, motility and death, are frequently transmitted through tyrosine kinases. To date, of the 90 tyrosine kinases, 58 are receptor tyrosine kinases (RTKs) characterized by a transmembrane domain and a tyrosine kinase motif $(5,6)$. RTKs, divided into 21 families, are membrane-bound proteins consisting of a ligand-binding domain at the extracellular surface, a single transmembrane segment and a cytoplasmic region harboring the protein kinase activity. The best known examples are the epidermal growth factor receptor (EGFR) family, the vascular endothelial growth factor receptor (VGEFR) subtypes, the fibroblast growth factor receptor (FGFR) family and the platelet-derived growth factor receptor (PDGF) family (7).

A relationship between human cancer and RTK activity has been established. Aberrant RTK activity has been detected in various human cancers including colon cancer (8-10). Therefore, instead of conventional chemotherapy, various RTK inhibitors are used for patients in the advanced stages of epithelial cancer and several clinical trials are exploring various designs to bring out the potential of RTK-targeting drugs $(11,12)$.

HER2 (human epidermal growth factor receptor) is the human ErbB2 homologue and a member of the ErbB family of receptors. There are 4 known members of the ErbB 
family, namely epidermal growth factor receptor (EGFR), HER2, HER3, HER4, that are expressed in various human tissues. These receptors are often deregulated in neoplasms and can promote proliferation, migration, angiogenesis, stromal invasion and resistance to apoptosis (13). HER2 overexpression has been previously reported in up to $85 \%$ of colon cancers; however, estimates vary depending on the methods used $(14,15)$. Few studies have shown that inhibition of HER2 signaling may have a new approach for the treatment of colon cancer (16).

Trastuzumab (Herceptin) targets ErbB2 and is used for treating ErbB2-overexpressing breast cancers. Initially, it was thought that engagement of HER2 by trastuzumab led to an increase in HER2 endocytosis or degradation rate (17). HER2 endocytosis was analyzed, and it was concluded that the monoclonal antibodies do not affect HER2 internalization or the rate of endocytosis $(18,19)$. In addition, trastuzumab does not block the association of ErbB2 with ligand-activatedErbB3 or EGFR (20). In cancer cells, trastuzumab disrupts the ligand-independent ErbB2/ErbB3/PI3K complexes and blocks Akt signaling $(21,22)$, which ultimately leads to an increase in the CDK2 inhibitor p27 $(23,24)$. Moreover, trastuzumab is shown to have no effect on the activation status of HER 2 or to cause a rapid increase or decrease of HER2 phosphorylation $(23,25,26)$. The aim of the present study was: i) to determine which RTKs are activated in colon cancer in vitro and in vivo; and ii) to investigate whether a RTK targeting drug candidate, trastuzumab is an effective agent in a colon cancer xenograft model.

\section{Materials and methods}

Cell culture and reagents. Caco-2, SW480, WiDr, Lovo colon cancer cell lines and CCD $841 \mathrm{CoN}$ a normal colon cell line were obtained as a kind gift of the Japanese Cancer Resource Bank (Tokyo, Japan), and used as the colon cancer cell lines. These cells were plated at a density of $1 \times 10^{5}$ cell $/ \mathrm{cm}^{3}$ in plastic flasks of Dulbecco's modified minimum essential medium (DMEM) (Gibco BRL Co., Grand Island, NY, USA) supplemented with $10 \%$ heat-inactivated fetal calf serum, penicillin $(100 \mathrm{mg} / \mathrm{ml})$ and $100 \mathrm{mg} / \mathrm{ml}$ streptomycin at $37^{\circ} \mathrm{C}$ in $5 \% \mathrm{CO}_{2}$ in air.

Patients. Three tissue samples of colon cancer were obtained from surgery ( 1 male and 2 females; mean age, 63.7 \pm 2.5 years; range, 61-66 years, all samples were classified as Dukes B). Tissues were frozen immediately at $-70^{\circ} \mathrm{C}$. None of the patients had received any chemotherapy or radiotherapy before surgery. Informed consent was obtained from each patient prior to participation and the experimental protocol was approved beforehand by the Human Subjects Committee of Kagawa University School of Medicine.

Cell lysate and tissue lysate. The lysate was prepared according to the methods described in our previous report (27-29). All steps were carried out at $4^{\circ} \mathrm{C}$. Protein concentration was measured using a dye-binding protein assay based on the Bradford method (27-29).

Materials for protein array. RayBio ${ }^{\mathrm{TM}}$ Human Phospho array kit (catalog no. ARY 001) was purchased from RayBiotech,
Inc. (Norcross, GA, USA). Proteome Profiler ${ }^{\mathrm{TM}}$ Array Human Phospho-MAPK array kit was purchased from R\&D Systems, Inc. (Minneapolis, MN, USA). Trastuzumab (Herceptin ${ }^{\mathrm{TM}}$ ) was purchased from Chugai Pharmaceutical Co. Ltd) (Tokyo, Japan).

Antibody arrays of phospho-RTK. The phospho-RTK array was performed according to the manufacturer's instructions. Briefly, phospho-RTK array membranes were blocked with $5 \%$ BSA/TBS (0.01 M Tris $\mathrm{HCl}, \mathrm{pH} 7.6)$ for $1 \mathrm{~h}$. Membranes were then incubated with $2 \mathrm{ml}$ of lysate prepared from cell lines or tissues after normalization with equal amounts of protein. After extensive washing with TBS including $0.1 \%$ v/v Tween-20, 3 times for $10 \mathrm{~min}$, and TBS alone, 2 times for $10 \mathrm{~min}$, to remove unbound material, the membranes were then incubated with anti-phospho-tyrosine-HRP antibody for $2 \mathrm{~h}$ at room temperature. The unbound HRP antibody was washed out with TBS including $0.1 \%$ Tween-20. Finally, each array membrane was exposed to X-ray film using a chemiluminescence detection system (Amersham Life Sciences, Tokyo, Japan). Densitometric analysis was determined using a Kodak Image Station (New Haven, CT). The analysis of the immunoblots was conducted in duplicate, and all the data were reproducible.

Phospho-MAPK antibody array. Assessing the phosphorylation status of all three major families of mitogen-activated protein kinases (MAPKs), the extracellular signal-regulated kinases (ERK1/2), c-Jun N-terminal kinases (JNK1-3) and different p38 isoforms $(\alpha / \beta / \delta / \gamma)$ is essential to understand the role of these signaling molecules in underlying cell function and disease. Apart from these intracellular kinases, other regulators of signal transduction, such as Akt, GSK-3 and p70 S6 kinase, are also important for mediating development and cell proliferation. In this method, capture and control antibodies have been spotted in duplicate on nitrocellulose membranes. Briefly, these membranes were blocked with $5 \%$ BSA/TBS (0.01 M Tris HCl, pH 7.6) for $1 \mathrm{~h}$. Membranes were then incubated with $200 \mu 1$ of lysate prepared from tumorous tissues after normalization with equal amounts of protein. After extensive washing with TBS including $0.1 \% \mathrm{v} / \mathrm{v}$ Tween-20, 3 times for $5 \mathrm{~min}$, to remove unbound materials, the membranes were then incubated with HRPphospho-MAPK antibody for $2 \mathrm{~h}$ at room temperature. Unbound HRP antibody was washed out with TBS including $0.1 \%$ Tween-20. Finally, each array membrane was exposed to X-ray film using a chemiluminescence detection system (Amersham Life Sciences, Tokyo, Japan).

In vivo antitumor effects of trastuzumab on colon cancer. Athymic 8-week-old male BALB/c-nu/nu mice, weighing 20-22 g, were purchased from Japan SLC (Hamamatsu, Japan) and kept under specific pathogen-free conditions at $24 \pm 2^{\circ} \mathrm{C}$. Animal experiments were performed with approved protocols and in accordance with the institutional recommendations for the proper care and use of laboratory animals. WiDr human colon cancer cells were suspended in PBS at a concentration of $5 \times 10^{7} \mathrm{cells} / \mathrm{ml}$, and $100 \mu \mathrm{l}$ inoculum volumes were injected subcutaneously into the flank regions of athymic BALB/c-nu/nu mice. When the tumor became palpable in the treated group $(\mathrm{n}=10), 500 \mu \mathrm{l}$ of PBS containing 


\begin{tabular}{|c|c|c|c|c|c|c|c|c|c|c|c|}
\hline Control & & & & & & & & & & & \\
\hline EGFR & ErbB2 & ErbB3 & ErbB4 & FGFR1 & $\begin{array}{c}\text { FGFR } \\
2 \mathrm{a}\end{array}$ & FGFR3 & FGFR4 & $\begin{array}{c}\text { Insuli } \\
\text { nR }\end{array}$ & $\begin{array}{c}\text { IGFR- } \\
\text { 1R }\end{array}$ & Axl & Dtk \\
\hline Mer & HGFR & MSPR & $\begin{array}{c}\text { PDGR } \\
\mathrm{a}\end{array}$ & PDGRb & SCFR & FIt3 & $\begin{array}{c}\text { M- } \\
\text { CSFR }\end{array}$ & c-Ret & ROR1 & ROR2 & Tie-1 \\
\hline TIE-2 & TrkA & TrkB & TrkC & $\begin{array}{c}\text { VEGFR } \\
1\end{array}$ & $\begin{array}{c}\text { VEGFR } \\
2\end{array}$ & $\begin{array}{c}\text { VEGF } \\
\text { R3 }\end{array}$ & MuSK & EphA1 & EphA2 & EphA3 & EphA4 \\
\hline EphA6 & EphB7 & EphB1 & EphB2 & EphB4 & EphB6 & $\begin{array}{c}\text { Mouse } \\
\text { IgG1 }\end{array}$ & $\begin{array}{c}\text { Mouse } \\
\text { IgG2A }\end{array}$ & $\begin{array}{c}\text { Mouse } \\
\text { IgG2B }\end{array}$ & $\begin{array}{c}\text { Goat } \\
\text { IgG }\end{array}$ & PBS & \\
\hline Control & & & & & & & & & & & Control \\
\hline
\end{tabular}

Antibody arrays of phospho-RTK

Figure 1. Template demonstrating the location of tyrosine kinase antibody spotted onto the RayBio Human phospho array kit.

A

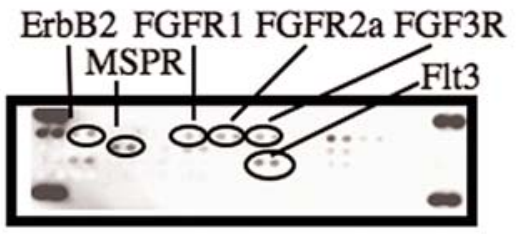

$\mathrm{CaCO}-2$
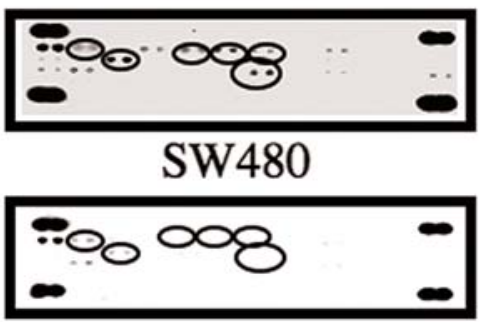

WiDr

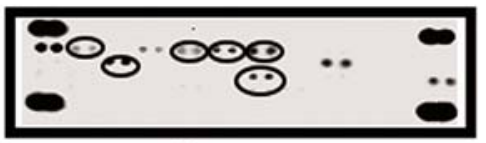

Lovo

Colon cancer cells
ErbB2 FGFR1 FGFR2a FGF3R

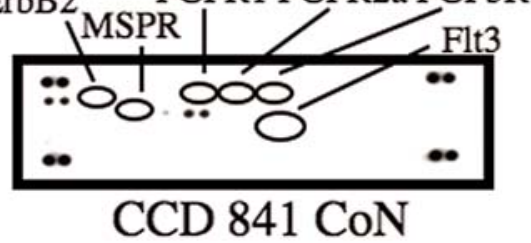

Normal colon epithelial cells

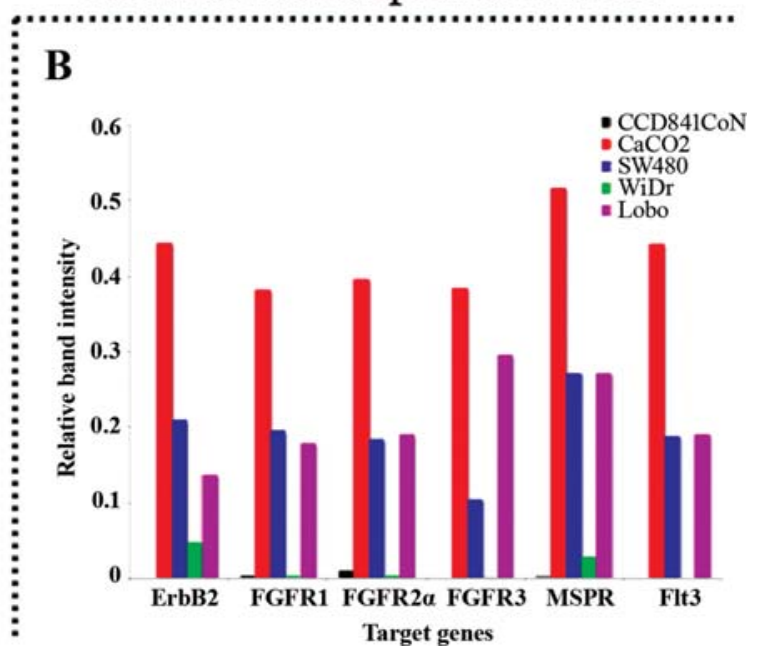

Figure 2. (A) Representative expression of various tyrosine kinases in colon cancer cell lines, CaCO-2, SW480, WiDr and Lovo and normal colon cell line, CCD841CoN. The upregulation of ErbB2 (black circle) was detected in all colon cell lines examined in this study. Especially, ErbB2 was specifically activated in all colon cancer cell lines studied in this study. The protein array methodology is described in the Materials and methods section. (B) Densitometric data on various phospho-RTK molecules in CaCO-2, SW480, WiDr and Lovo were expressed as red, blue, green and purple bars, respectively. Significantly elevated levels ( $>10$-fold increase densitometric data) of ErbB2 and MSPR were detected in all cancer cell lines when compared with the normal colon cell line, CCD841CoN.

$1.5 \mathrm{mg} / 0.5 \mathrm{ml}$ trastuzumab (Herceptin, directed against the ErbB2 receptor, also known as Her2/neu oncogene), was administered intraperitoneally for three weeks, three times a week. Only PBS was administrated to the control group $(n=10)$. After the initiation of the administration of trastuzumab, the tumor growth was monitored by the same investigators (A.M., T.M), and the tumor diameters were measured every week using a graduated caliper. Tumor growth was assessed weekly by measuring the two greatest perpendicular tumor dimensions. Tumor volume was calculated as follows: tumor volume $\left(\mathrm{mm}^{3}\right)=$ [tumor length $(\mathrm{mm}) \mathrm{x}$ tumor width $\left.(\mathrm{mm})^{2}\right] / 2$. All animals were sacrificed on day 14 after treatment. All animals were alive during the observation period.

Statistical analysis. Results are expressed as means \pm SD. All analyses were performed using the computer-assisted StatView program (SAS Institute, Cary, NC, USA). Paired analysis between each group (trastuzumab, 5-FU, those mixed) and control groups were performed using the t-test. $\mathrm{p}=0.05$ was considered to indicate a significant difference between groups.

\section{Results}

The activity level of tyrosine-activated receptor tyrosine kinases (RTKS) associated with colon cancer. Enhanced phospho-RTKs were detected by a phospho-RTKs antibody array system analyzing colon cancer cells. By using this array, the expressions of 42 different activated RTKs were simultaneously screened (Fig. 1). Compared with normal colon epithelial cells, CCD $841 \mathrm{CoN}$, the RTKs activated in all the colon cancer cell lines except WiDr were ErbB2, 


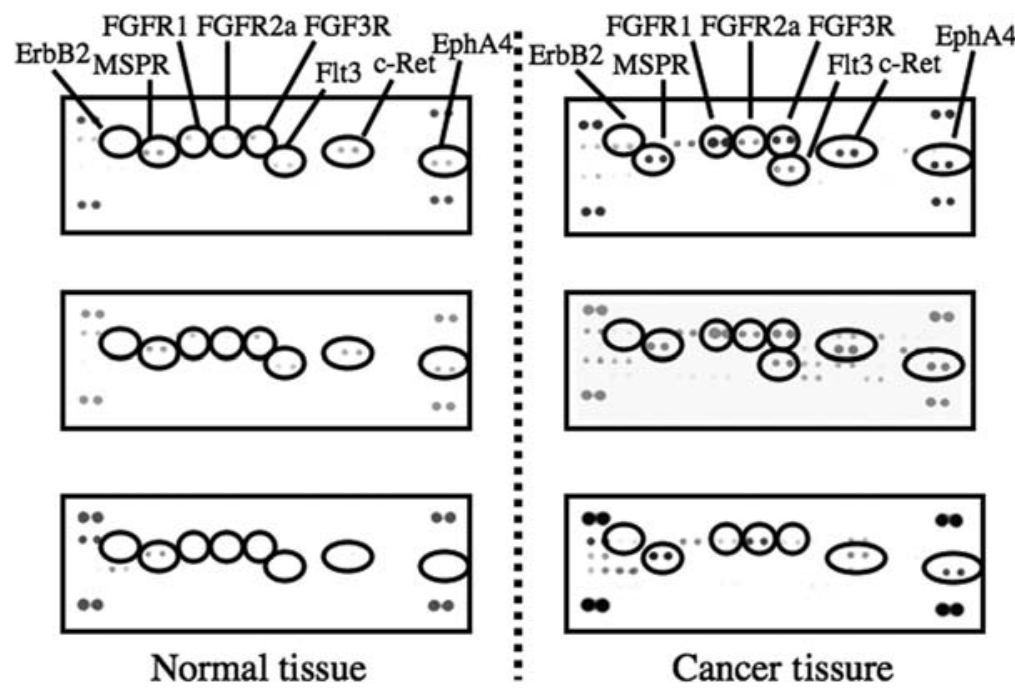

Figure 3. Representative sample results $(n=3)$ revealing a marked increase of ErbB2, FGFR1, FGFR2a, FGFR3, c-Ret, MSPR, Flt3 and Eph-4 activation in cancerous tissue when compared with pair-matched normal colon mucosa.

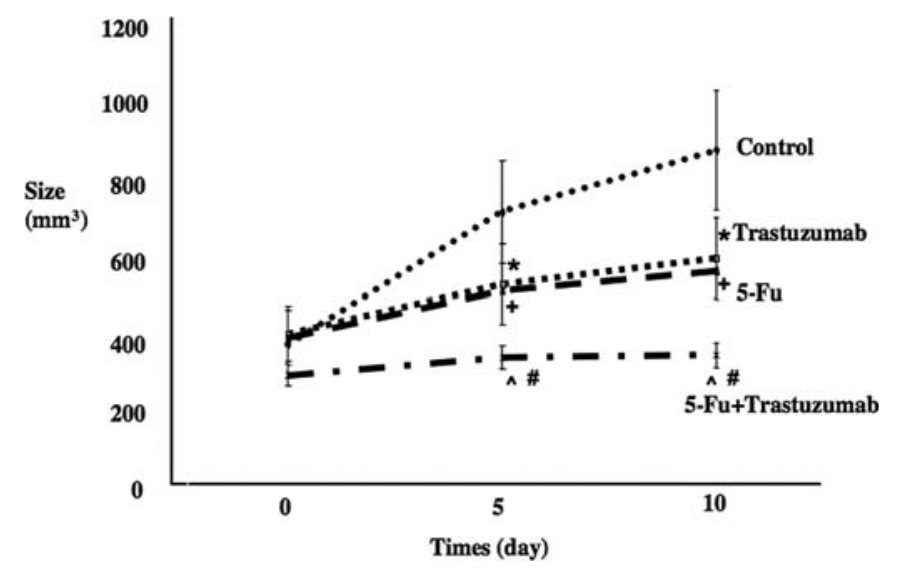

Figure 4. In vivo antitumor effects of trastuzumab on established colon cancer in nude mice. WiDr cells implanted subcutaneously into the flank region of nude mice. When tumors became palpable, $1.5 \mathrm{mg} / 0.5 \mathrm{ml}$ of trastuzumab and $1.0 \mathrm{mg} / 0.5 \mathrm{ml}$ of 5 -FU were injected intraperitoneally for two weeks, three times a week. Animal in the control group developed rapidly growing subcutaneous colon cancer tumors. In contrast, animals in the trastuzumab $\left({ }^{*} \mathrm{p}<0.05\right)$ - 5 -FU $\left({ }^{+} \mathrm{p}<0.05\right)$, and combination therapy groups $(\hat{p}<0.05)$ exhibited significantly retarded tumor development compared with animals in the control group. In addition, the combination group of trastuzumab and 5-FU $\left({ }^{*} \mathrm{p}<0.05\right)$ significantly inhibited the growth of the tumor compared with trastuzumab alone and 5-FU alone groups. Each data point represents the mean \pm SD of 10 animals. ${ }^{*} \mathrm{p}<0.05$.

FGFR1, FGFR2a, FGFR3, MSPR and Flt3 (Fig. 2A). Among these activated RTKs in colon cancer cell lines, ErbB2 and MSPR were also activated in all the four colon cancer cell lines, including WiDr (Fig. 2A and B).

In the case of human colon cancer tissues, ErbB2, FGFR1, FGFR2a, FGFR3, MSPR, Flt3, c-Ret and EphA4 were activated compared with the levels in normal mucosa. These activated RTKs except Flt3 were detected in all cancerous samples (three cases) used in this study (Fig. 3). These results suggest that an ErbB2-targeting drug may be a useful agent for the treatment of colon cancer.
In vivo antitumor effects of ErbB2-targeting drug, trastuzumab. Athymic 8-week-old male BALB/c-nu/nu mice were implanted subcutaneously with WiDr. When the animals developed palpable tumors, they were treated intraperitoneally for two weeks, three times a week with drug. Animals in the control group received intraperitoneal administration of the vehicle (PBS). As shown in Fig. 4, animals in the control group developed rapidly growing subcutaneous colon cancer. In contrast, animals in the trastuzumab alone group, 5-FU alone group and those in the mixed group exhibited significantly retarded tumor development compared with animals in the control group (Fig. 4). Interestingly, the animals in the mixed group (trastuzumab and 5-FU) exhibited retarded tumor growth when compared with the animals in the trastuzumab alone and 5-FU alone group (Fig. 4). Furthermore, animals in the trastuzumab, 5-FU and those in the mixed treatment group did not exhibit any gross physical changes, while those in the control group demonstrated disheveled fur and diminished body weight. All animals remained alive throughout the experiment.

Expression of various MAPK antigens in WiDr tumor tissues. The expression of $\mathrm{PKB} \gamma / \mathrm{Akt} 3$ in the tumorous tissue was reduced by treatment with trastuzumab, 5-FU and combination therapy as detected by phospho-MAPK protein arrays (Figs. 5, 6A and B). The human phospho-MAPK array could simultaneously screen 21 different molecules (Fig. 5). The expression ratio of $\mathrm{PKB} \gamma / \mathrm{Akt} 3$ in trastuzumab, 5-FU and the combined groups was $1.57,6.25$ and $1.30 \%$ of the control, respectively (Fig. 6B).

\section{Discussion}

The human epidermal growth factor receptor 2 (HER2) gene, also known as ErbB-2 encodes a $185-\mathrm{kDa}$ transmembrane glycoprotein receptor. This receptor belongs to the ErbB family of growth factor receptors with intrinsic tyrosine kinase activity, the members of which exist in homodimer 


\begin{tabular}{|c|c|c|c|c|c|c|c|c|c|c|}
\hline $\begin{array}{l}\text { Ctrl } \\
(+)\end{array}$ & & & & & & & & & & $\begin{array}{l}\text { Ctrl } \\
(+)\end{array}$ \\
\hline & ERK1 & JNK1 & JNK pan & P38\% & P388 & RSK1 & $\underset{\alpha / \beta}{\text { GSK-3 }}$ & $\begin{array}{l}\text { PKB } \alpha, \\
\text { Akt1 }\end{array}$ & $\begin{array}{l}\text { PKB } \beta, \\
\text { Akt2 }\end{array}$ & \\
\hline & ERK2 & JNK2 & - & P38 $\alpha$ & P38 $\beta$ & RSK2 & GSK-3 $\beta$ & $\begin{array}{l}\text { PKB\%, } \\
\text { Akt3 }\end{array}$ & Akt pan & \\
\hline & & JNK3 & MSK2 & & & & HSP27 & $\begin{array}{l}\text { P70 S6 } \\
\text { Kinase }\end{array}$ & & \\
\hline & $\begin{array}{c}\text { Rabbit } \\
\text { IgG }\end{array}$ & $\begin{array}{c}\text { Mouse } \\
\text { IgG1 }\end{array}$ & $\begin{array}{l}\text { Mouse } \\
\text { IgG2A }\end{array}$ & $\begin{array}{l}\text { Mouse } \\
\text { IgG2B }\end{array}$ & $\begin{array}{l}\text { Goat } \\
\text { IgG }\end{array}$ & PBS & & & & \\
\hline $\begin{array}{l}\text { Ctrl } \\
(+)\end{array}$ & & & & & & & & & & \\
\hline
\end{tabular}

Human Phopho-MAPK Array

Figure 5. Template demonstrating the location of antibodies to phospho-MAPK antigens spotted onto the Proteome Profiler human phospho-MAPK array kit. Ctrl, Control; ERK, extracellular signal-regulated kinase, JNK; c-Jun N-terminal kinase; RSK, p90 ribosomal S6 kinase; GSK, glycogen synthase kinase; PKB/Akt, protein kinases B; MSK, mitogen- and stress-activated kinase 2, HSP27, heat shock protein 27, P70 S6 kinase, ribosomal S6 protein kinase.

A.

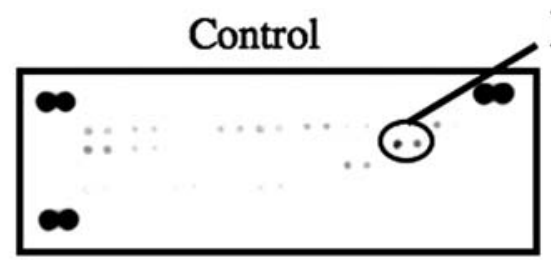

Trastuzumab

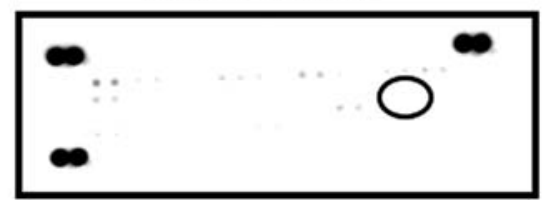

Trastuzumab $+5 \mathrm{FU}$

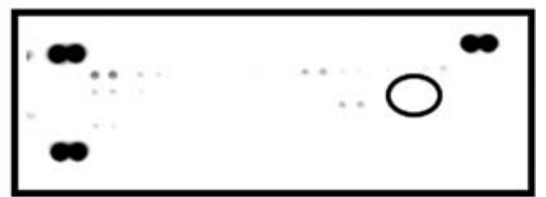

B.

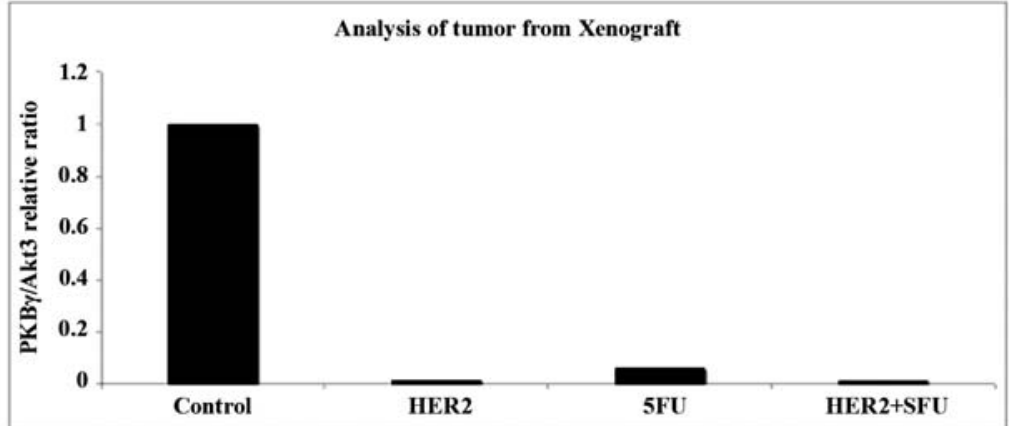

Human Phospho-MAPK Array

Figure 6. (A) Representative expression of various phospho-MAPK antigens in WiDr tumor tissue in nude mice treated with trastuzumab, 5-FU, combination therapy and control. Marked reduction of PKB $\gamma / \mathrm{Akt} 3$ phosphorylation was observed in the drug-added groups when compared to control. (B) The expression of $\mathrm{PKB} \gamma / \mathrm{Akt} 3$ in the tumorous tissue of trastuzumab, 5-FU and combination therapy nude mice were $1.57,6.25$ and $1.30 \%$ of the control, respectively.

and heterodimer form when activated (29). Overexpression of HER2 has been detected in up to $25-30 \%$ of human breast cancers $(30,31)$, and found in $11-83 \%$ of human colon cancers $(14,15,32)$. Therefore, HER2 has been successfully targeted in breast cancer utilizing antibodies directed against the extracellular domains but the evidence supporting a potential role for trastuzumab in colorectal carcinoma has not been demonstrated (32). On the other hand, in experimental models, trastuzumab suppresses the growth of colon cancer cell lines with HER2 overexpression in vitro and in vivo (33).
Several clinical trials are exploring different settings in colon cancer patients with HER2 over-expression (34). However, to date, the mechanism of the growth suppression of trastuzumab for colon cancer cells remains unknown. In the present study, we examined the relationship between the antitumor effect of trastuzumab with 5-FU and the expressions of phospho-MAPK molecules.

Our studies demonstrated that ErbB2 and MSPR were activated in all four of the human colon cancer cell lines and all human colon cancer tissues and ErbB2, FGFR1, FGFR2a, 
FGFR3, Flt3 were detected in all of the colon cancer cell lines except WiDr. In addition, c-Ret and EphA4 were also activated in human colon cancer tissue. Overexpression of ErbB2, FGFR1, FGFR2a, c-Ret and EphA4 have already been reported in various cancers including colon cancer (14,35-39). These reports support our result on the various RTKs detected from the protein array used in this study. Furthermore, inhibition of activated RTKs actually retarded tumor growth in a xenograft model. These results suggest that there are several phenotypes of phospho-RTKs expression in colon cancer in vitro and in vivo and the immunological inhibition of ErbB2 and MSPR may have an antitumor effect for colon cancer. Therefore, the analysis of phospho-RTK expression by the protein array as a useful tool might lead to appropriate therapy for individual patients with colon cancer.

To date, there are two antitumor mechanisms proposed for the therapeutic effect of trastuzumab: a direct antiproliferative effect via the blockade of signaling pathways, downmodulation of the ErbB2 protein, and activation of apoptotic signals of the tumor cells, and an indirect antitumor effect by antibody-dependent cell-mediated cytotoxicity $(40,41)$. Our results indicated that the expression of phospho-MAPK molecules, such as PKB $\gamma / \mathrm{Akt} 3$, was reduced by treatment with trastuzumab, indicating that trastuzumab may inhibit the expression of phospho-MAPK molecules of WiDr cells in vivo. These data suggest that the antitumor effect of the ErbB2-targeting drug trastuzumab may be due to the reduction of the phospho-MAPK molecule.

Recently, it has become clear that despite the specificity achieved with immunotherapy against cancers, a single modality is insufficient to eradicate such a difficult disease. Combinations of different types of immunotherapy and chemotherapy have been tested, with the suggestion of improved efficacy to spur further clinical trials $(42,43)$. Extensive clinical trials with the combination of chemotherapy and trastuzumab have shown that the anti-breast cancer reagents doxorubicin, paclitaxel and vinorelbine all potentiate the activity of trastuzumab (44). However, to date, the effect of such combinations in colon cancer remain unknown. In the present study, we used 5-FU and trastuzumab as a new combination. Under these conditions trastuzumab effectively inhibited tumor development in the group with combination therapy compared to the group with a single drug in the xenograft model. These results suggest that the combination of trastuzumab and 5-FU might extend the possibility of new therapy for 5-FU resistant colon cancer.

In conclusion, our findings demonstrate that the expressions of $\mathrm{PKB} \gamma / \mathrm{Akt} 3$ in colon cancer are regulated by ErbB2 activity, and suggest an additional mechanism for the contribution of the ErbB2-targeting drug trastuzumab in the inhibition of tumor proliferation through the ErbB2-PKB $\gamma /$ Akt3 signaling pathway. The feasibility of utilizing protein arrays in this study suggests that its arrays might be a useful tool for detecting the expression of activated RTKs and identifying novel therapies for colon cancer.

\section{References}

1. Parkin DM, Bray F, Ferlay J and Pisani P: Estimating the world cancer burden: Globocan 2000. Int J Cancer 94: 153-156, 2001.
2. Devine RM and Dozois RR: Surgical management of locally advanced adenocarcinoma of the rectum. World J Surg 16: 486-489, 1992

3. Izbicki JR, Hosch SB, Knoefel WT, Passlick B, Bloechle C and Broelsch CE: Extended resections are beneficial for patients with locally advanced colorectal cancer. Dis Colon Rectum 38: 1251-1256, 1995.

4. Wang Y, Cummings B, Catton P, et al: Primary radical external beam radiotherapy of rectal adenocarcinoma: long term outcome of 271 patients. Radiother Oncol 77: 126-132, 2005

5. Robertson SC, Tynan J and Donoghue DJ: RTK mutations and human syndromes: when good receptors turn bad. Trends Genet 16: 368,2000

6. Robinson DR, Wu YM and Lin SF: The protein tyrosine kinase family of the human genome. Oncogene 19: 5548-5557, 2000.

7. Becker JC, Muller-Tidow C, Serve H, Domschke W and Pohle T: Role of receptor tyrosine kinases in gastric cancer: new targets for a selective therapy. World J Gastroenterol 12: 3297-3305, 2006.

8. Prenzel N, Zwick E, Leserer M and Ullrich A: Tyrosine kinase signalling in breast cancer. Epidermal growth factor receptor: convergence point for signal integration and diversification. Breast Cancer Res 2: 184-190, 2000.

9. Tanner M, Hollmen M, Junttila TT, et al: Amplification of HER-2 in gastric carcinoma: association with Topoisomerase IIalpha gene amplification, intestinal type, poor prognosis and sensitivity to trastuzumab. Ann Oncol 16: 273-278, 2005.

10. Svensson S, Jirstrom K, Ryden L, et al: ERK phosphorylation is linked to VEGFR2 expression and Ets-2 phosphorylation in breast cancer and is associated with tamoxifen treatment resistance and small tumours with good prognosis. Oncogene 24: 4370-4379, 2005

11. Shawver LK, Slamon D and Ullrich A: Smart drugs: tyrosine kinase inhibitors in cancer therapy. Cancer Cell 1: 117-123, 2002.

12. Cao C, Albert JM, Geng L, et al: Vascular endothelial growth factor tyrosine kinase inhibitor AZD2171 and fractionated radiotherapy in mouse models of lung cancer. Cancer Res 66: 11409-11415, 2006.

13. Marmor MD, Skaria KB and Yarden Y: Signal transduction and oncogenesis by ErbB/HER receptors. Int J Radiat Oncol Biol Phys 58: 903-913, 2004.

14. Dursun A, Poyraz A, Suer O, Sezer C and Akyol G: Expression of Bcl-2 and c-ErbB-2 in colorectal neoplasia. Pathol Oncol Res 7: 24-27, 2001

15. Ross JS and McKenna BJ: The HER-2/neu oncogene in tumors of the gastrointestinal tract. Cancer Invest 19: 554-568, 2001.

16. Mann M, Sheng H, Shao J, et al: Targeting cyclooxygenase 2 and HER-2/neu pathways inhibits colorectal carcinoma growth. Gastroenterology 120: 1713-1719, 2001.

17. Hudziak RM, Lewis GD, Winget M, Fendly BM, Shepard HM and Ullrich A: p185HER2 monoclonal antibody has antiproliferative effects in vitro and sensitizes human breast tumor cells to tumor necrosis factor. Mol Cell Biol 9: 1165-1172, 1989.

18. Austin CD, De Maziere AM, Pisacane PI, et al: Endocytosis and sorting of ErbB2 and the site of action of cancer therapeutics trastuzumab and geldanamycin. Mol Biol Cell 15: 5268-5282, 2004.

19. Hommelgaard AM, Lerdrup M and van Deurs B: Association with membrane protrusions makes ErbB2 an internalizationresistant receptor. Mol Biol Cell 15: 1557-1567, 2004.

20. Agus DB, Akita RW, Fox WD, et al: Targeting ligand-activated ErbB2 signaling inhibits breast and prostate tumor growth. Cancer Cell 2: 127-137, 2002.

21. Hynes NE and Dey JH: PI3K inhibition overcomes trastuzumab resistance: blockade of ErbB2/ErbB3 is not always enough. Cancer Cell 15: 353-355, 2009.

22. Junttila TT, Akita RW, Parsons K, et al: Ligand-independent HER2/HER3/PI3K complex is disrupted by trastuzumab and is effectively inhibited by the PI3K inhibitor GDC-0941. Cancer Cell 15: 429-440, 2009.

23. Lane HA, Beuvink I, Motoyama AB, Daly JM, Neve RM and Hynes NE: ErbB2 potentiates breast tumor proliferation through modulation of p27(Kip1)-Cdk2 complex formation: receptor overexpression does not determine growth dependency. Mol Cell Biol 20: 3210-3223, 2000.

24. Lee H, Akita RW, Sliwkowski MX and Maihle NJ: A naturally occurring secreted human ErbB3 receptor isoform inhibits heregulin-stimulated activation of ErbB2, ErbB3, and ErbB4. Cancer Res 61: 4467-4473, 2001. 
25. Nagata Y, Lan KH, Zhou X, et al: PTEN activation contributes to tumor inhibition by trastuzumab, and loss of PTEN predicts trastuzumab resistance in patients. Cancer Cell 6: 117-127, 2004.

26. Masaki T, Tokuda M, Yoshida S, et al: Comparison study of the expressions of myristoylated alanine-rich $\mathrm{C}$ kinase substrate in hepatocellular carcinoma, liver cirrhosis, chronic hepatitis, and normal liver. Int J Oncol 26: 661-671, 2005.

27. Yoshida S, Masaki T, Feng H, et al: Enhanced expression of adaptor molecule p46 Shc in nuclei of hepatocellular carcinoma cells: study of LEC rats. Int J Oncol 25: 1089-1096, 2004.

28. Yukimasa S, Masaki T, Yoshida S, et al: Enhanced expression of p46 Shc in the nucleus and p52 Shc in the cytoplasm of human gastric cancer. Int J Oncol 26: 905-911, 2005.

29. Friedlander E, Barok M, Szollosi J and Vereb G: ErbB-directed immunotherapy: antibodies in current practice and promising new agents. Immunol Lett 116: 126-140, 2008.

30. Slamon DJ, Clark GM, Wong SG, Levin WJ, Ullrich A and McGuire WL: Human breast cancer: correlation of relapse and survival with amplification of the HER-2/neu oncogene. Science 235: 177-182, 1987.

31. Slamon DJ, Godolphin W, Jones LA, et al: Studies of the HER$2 /$ neu proto-oncogene in human breast and ovarian cancer. Science 244: 707-712, 1989.

32. Kavanagh DO, Chambers G, O'Grady L, et al: Is overexpression of HER-2 a predictor of prognosis in colorectal cancer? BMC Cancer 9: 1, 2009.

33. Kuwada SK, Scaife CL, Kuang J, et al: Effects of trastuzumab on epidermal growth factor receptor-dependent and -independent human colon cancer cells. Int J Cancer 109: 291-301, 2004.

34. Sartor CI: Epidermal growth factor family receptors and inhibitors: radiation response modulators. Semin Radiat Oncol 13: 22-30, 2003.

35. Shin EY, Lee BH, Yang JH, et al: Up-regulation and coexpression of fibroblast growth factor receptors in human gastric cancer. J Cancer Res Clin Oncol 126: 519-528, 2000.
36. Zhang Y, Zhang J, Lin Y, et al: Role of epithelial cell fibroblast growth factor receptor substrate 2alpha in prostate development, regeneration and tumorigenesis. Development 135: 775-784, 2008.

37. Cetta F, Chiappetta G, Melillo RM, et al: The ret/ptc1 oncogene is activated in familial adenomatous polyposis-associated thyroid papillary carcinomas. J Clin Endocrinol Metab 83: 1003-1006, 1998.

38. Oki M, Yamamoto $\mathrm{H}$, Taniguchi $\mathrm{H}$, Adachi $\mathrm{Y}$, Imai $\mathrm{K}$ and Shinomura Y: Overexpression of the receptor tyrosine kinase EphA4 in human gastric cancers. World J Gastroenterol 14: 5650-5656, 2008.

39. Iiizumi M, Hosokawa M, Takehara A, et al: EphA4 receptor, overexpressed in pancreatic ductal adenocarcinoma, promotes cancer cell growth. Cancer Sci 97: 1211-1216, 2006.

40. Sliwkowski MX, Lofgren JA, Lewis GD, Hotaling TE, Fendly BM and Fox JA: Nonclinical studies addressing the mechanism of action of trastuzumab (Herceptin). Semin Oncol 26: 60-70, 1999.

41. Cuello M, Ettenberg SA, Clark AS, et al: Down-regulation of the erbB-2 receptor by trastuzumab (herceptin) enhances tumor necrosis factor-related apoptosis-inducing ligand-mediated apoptosis in breast and ovarian cancer cell lines that overexpress erbB-2. Cancer Res 61: 4892-4900, 2001.

42. Mitchell MS: Immunotherapy as part of combinations for the treatment of cancer. Int Immunopharmacol 3: 1051-1059, 2003.

43. Mitchell MS: Combinations of anticancer drugs and immunotherapy. Cancer Immunol Immunother 52: 686-692, 2003.

44. Slamon DJ, Leyland-Jones B, Shak S, et al: Use of chemotherapy plus a monoclonal antibody against HER2 for metastatic breast cancer that overexpresses HER2. N Engl J Med 344: 783-792, 2001. 